\begin{tabular}{|l|r|}
\hline MANAJEMEN & $\begin{array}{r}\text { p-ISSN } 1858-1048 \\
\text { e-ISSN } 2654-9247\end{array}$ \\
KEWIRAUSAHAAN & $\begin{array}{r}\text { http://ejurnal.stieipwija.ac.id/index.php/jmk } \\
\text { DOI: http://dx.doi.org/10.33370/jmk.v17i2.453 }\end{array}$ \\
\hline
\end{tabular}

\title{
ANALISIS LOKASI, HARGA, DAN PROMOSI TERHADAP KEPUTUSAN PEMBELIAN RUMAH DI PERUMAHAN CINERE PARKVIEW
}

\section{(ANALYSIS OF EFFECT LOCATIONS, PRICES, AND PROMOTIONS ON PURCHASE DECISIONS AT CINERE PARKVIEW HOUSINGS)}

\author{
Oleh: \\ Joni Heruwanto ${ }^{1)}$, Rista Kusumanadya'), Rasipan ${ }^{3)}$, Ergo Nurpatria Kurniawan ${ }^{4)}$ \\ joniheruwanto@yahoo.com ${ }^{1}$; ;istakusuma26@gmail.com ${ }^{2}$; ipan081267@yahoo.com ${ }^{3}$ ); \\ ergo.mustgo@gmail.com ${ }^{4}$ \\ Sekolah Tinggi Ilmu Ekonomi IPWI Jakarta1,2)
}

\begin{abstract}
ABSTRAK
Tujuan penelitian ini menganalisis pengaruh beberapa faktor seperti lokasi, harga, dan promosi terhadap keputusan untuk pembelian rumah di Perumahan Cinere Parkview yang dibangun oleh PT Megapolitan Development. Penelitian ini menggunakan analisis regresi linier berganda dengan menggunakan program SPSS Versi 16.O. Populasi yang digunakan merupakan masyarakat yang menghuni atau tinggal di Perumahan Cinere Parkview. Sedangkan sampel yang digunakan sebanyak 100 orang dengan metode proportional sampling. Berdasarkan analisis digunakan, dapat ditarik kesimpulan bahwa penelitian ini memenuhi syarat validitas, reliabilitas, serta bebas dari heteroskedastisitas, multikolinearitas, dan telah lolos uji normalitas. Pengujian hipotesis menggunakan uji t didapatkan hasil bahwa variabel lokasi, harga, dan promosi secara signifikan mempengaruhi keputusan suatu pembelian. Sedangkan pada pengujian $F$ menunjukkan hasil signifikan <0,05. Hal ini menunjukan variable dalam penelitian berpengaruh positif terhadap keputusan pembelian, sedangkan koefisien determinasi diperoleh nilai Adjusted $R^{2} 73,9 \%$.
\end{abstract}

Kata kunci: Harga; Keputusan Pembelian; Lokasi; Promosi

\begin{abstract}
The purpose of this research is to analyze the influence of several factors such as location, price, and promotion on the decision to purchase a house in the Cinere Parkview Housing built by PT. Megapolitan Development. This research used multiple linear regression analysis using the SPSS Version 16.0 program. The population used is the people who inhabit or live in the Cinere Parkview Housing. While the sample used was 100 people with the proportional sampling method. Based on the analysis used, it can be concluded that this study meets the requirements of validity, reliability, and is free from heteroscedasticity, multicollinearity, and has passed the normality test. Hypothesis testing using the t test shows that the variable location, price, and promotion significantly affects a purchase decision. While the f test shows significant results $<0.05$. This shows that the variables in the study have a positive effect on purchasing decisions, while the coefficient of determination is obtained by the value of Adjusted $R^{2} 73.9 \%$.
\end{abstract}

Keywords: Location; Price; Promotion; Purchase Decision

Jurnal Manajemen Kewirausahaan Vol. 17 No. 02 - Desember 2020

LP2M Sekolah Tinggi Ilmu Ekonomi IPWI Jakarta 


\section{PENDAHULUAN}

Pembangunan permukiman di Kota Depok khususnya di Cinere saat ini sedang mengalami peningkatan yang cukup tinggi. Peningkatan jumlah penduduk yang semakin pesat pada setiap tahunnya, diimbangi dengan semakin pesatnya tempat bemukim untuk terpenuhinya tempat tinggal bagi masyarkat. Semakin tinggi jumlah penduduk pada satu wilayah akan menyebabkan melonjaknya jumlah permintaan akan lahan pemukiman dan akses publik yang mudah untuk diakses.

Fenomena yang terjadi pada pemukiman di Cinere saat ini adalah padatnya populasi, semakin mudahnya akses transportasi, dibalik itu semua terjadi peningkatan harga properti yang semakin melonjak. Diperkirakan untuk dua puluh tahun yang akan datang dari sebanyak 266,91 ribu jiwa pada tahun 2019 akan menjadi sebanyak 303.996,70 ribu jiwa pada tahun 2034 yang akan datang, hal ini selaras dengan peningkatan pertumbuhan ekonomi yang ada pada Indonesia, tercatat akan mengalami kenaikan sebesar $5,07 \%$ pada tahun 2019 dimana sebelumya pada tahun 2018 sebesar 5,06\%.

Sampai saat ini permasalahan rumah hunian masih menjadi suatu permasalahan besar di wilayah Indonesia. Permasalahan tempat rumah hunian yang dirasakan oleh penduduk yang jauh dari kota-kota besar di wilayah Indonesia adalah lemahnya daya beli masyarakat akan rumah hunian yang layak dan sehat. Hal ini sangat berbanding terbalik dengan permasalahan yang selalu dirasakan bagi penduduk kota-kota besar yang ada di wilayah Indonesia, yaitu terbatasnya lahan untuk membuat tempat tinggal atau hunian di kota besar yang menyebabkan tingginya harga rumah hunian dan menyebabkan semakin sulit masyarakat mendapatkannya.

$\begin{array}{ccc}\text { Menurut } & \text { Kotler } & (2007: 223) \\ \text { dalam } & \text { melakukan }\end{array}$

pengambilan keputusan untuk membeli tidak secara langsung dapat dilakukan, namun harus melalui beberapa proses yang disebut dengan buyer decision process, yaitu suatu proses yang harus dilakukan oleh seseorang sebelum memutuskan untuk membeli rumah". Hal ini menyebabkan banyak bermunculan bisnis pada bidang properti, yang menyebabkan banyaknya pengelola properti yang bermunculan dengan memberikan berbagai macam pilahan fasilitas rumah hunian yang memanjakan calon pembeli.

PT Megapolitan Developments Tbk, didirikan sejak tahun 1976, perusahaan tersebut telah berkontribusi secara luas dalam pembangunan berbagai kawasan tempat tinggal atau hunian, komersial, dan pusat bisnis yang ada pada wilayah Jakarta, Cinere, Karawaci, dan Sentul. Berbagai macam kawasan hunian maupun komersial di wilayah Cinere, Karawaci, dan Sentul merupakan bukti kapasitas PT Megapolitan Developments Tbk dalam menyediakan berbagai macam properti yang prospektif bagi masyarakat yang ada di Indonesia. Seiring dengan berkembangnya PT Megapolitan Developments Tbk memilik misi untuk menjadi pengembang unggulan dengan membangun mahakarya secara berkesinambungan demi mensejahterakan semua pemangku kepentingan.

PT Megapolitan Development Tbk merupakan salah satu perusahaan pengembangan pemukiman atau perumahan yang menyediakan tempat tinggal atau hunian dengan berbagai macam tipe. Pemasaran perumahan yang di lakukan oleh perusahaan pada umumnya dengan menggunakan cara penawaran yang serupa dengan bisnis properti lainnya. PT Megapolitan Development Tbk memberikan penawaran pemukiman yang diberi nama Cinere Parkview dimana pemukiman ini memiliki beberapa keunggulan yang menonjol seperti tempat yang dekat dengan lokasi lainnya, aksesnya pemukiman yang mudah, nyaman untuk ditempati, bebas dari polusi, rumah hunian yang hanya menggunakan akses satu pintu keluar dan masuk.

\section{TUJUAN PENELITIAN}

Tujuan penelitian ini adalah: 1) Untuk mengetahui apakah faktor lokasi, 
harga, dan promosi berpengaruh terhadap keputusan calon pembeli rumah yang ada di Cinere Parkview. 2) Untuk mengetahui pengaruh dominan terhadap faktor lokasi, harga, dan promosi yang memiliki pengaruh yang kuat terhadap keputusan pembelian tempat tinggal atau hunian yang ada di Cinere Parkview.

\section{TELAAH LITERATUR DAN PENGEMBANGAN HIPOTESIS}

Menurut Stanton, (2000:35)

"Pemasaran adalah suatu sistem keseluruhan ditunjukan untuk merencanakan, menetukan harga, mempromosikan, dan mendistribusikan barang dan jasa untuk memuaskan kebutuhan baik kepada pembeli yang ada maupun pembeli yang potensial."

Menurut Kotler dan Keller (2009:5) bahwa "Pemasaran adalah fungsi organisasi dan serangkaian proses untuk menciptakan, mengkomunikasikan, dan memberikan nilai kepada pelanggan untuk mengelola hubungan pelanggan dengan cara yang menguntungkan organisasi dan pihak-pihak yang berkepentingan terhadap organisasi". Sedangkan menurut Tjiptono (2008:5) "Pemasaran merupakan fungsi yang memiliki kontak paling besar dengan lingkungan eksternal, padahal perusahaan hanya memiliki kendali yang terbatas terhadap lingkungan eksternal".

\section{Lokasi}

Lokasi menurut Tjiptono (2015:345) "Lokasi merupakan berbagai aktivitas pemasaran yang berusaha memperlancar dan mempermudah penyampaian atau penyaluran barang dan jasa dari produsen kepada konsumen". Pilihan lokasi merupakan faktor bersaing dalam usaha menarik pelanggan. Perusahaanperusahaan menggunakan aneka ragam metode untuk menentukan lokasi, termasuk perhitungan transportasi, penelitian yang didasarkan pada kebiasaan belanja pelanggan, metode analisis lokasi, dan sebagainya.

\section{Harga}

Menurut Swastha \& Irawan (2008:241) harga adalah "Jumlah uang (ditambahkan beberapa barang kalau mungkin) yang dibutuhkan utuk mendapatkan sejumlah kombinasi dari barang beserta pelayanannya”. Sedangkan menurut Kotler dan Amstrong (2001:466) "Harga adalah sejumlah uang yang ditukarkan untuk produk dan jasa".

\section{Promosi}

Menurut Alma (2011:179) "Promosi adalah sejenis komunikasi yang memberi penjelasan yang menyakinkan calon konsumen tentang barang dan jasa". Selanjutnya Kotler (2002:41) menyatakan bahwa "Promosi adalah berbagai kegiatan yang dilakukan oleh perusahaan yang menonjolkan keistimewaan produknya yang membujuk konsumen sasaran agar membelinya".

\section{Kerangka Penelitian}

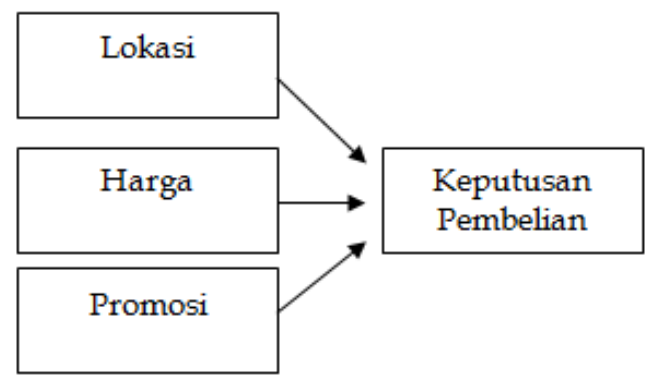

Gambar 1. Kerangka Penelitian

\section{METODE PENELITIAN}

Penelitian ini dilakukan di Perumahan Cinere Parkview.

\section{Populai Penelitian}

"Populasi merupakan wilayah generalisasi yang terdiri atas subyek atau obyek yang mempunyai kuantitas dan karakteristik yang ditetapkan oleh peneliti untuk dipelajari dan kemudian ditarik kesimpulannya" menurut Sugiyono (2010:117). Populasi yang ada pada penelitian ini merupakan pembeli yang sudah membeli hunian yang ada di 
perumahan Cinere Parkview, yang jumlahnya sebanyak 137 .

\section{Sampel Penelitian}

Menurut Sugiono (2014:148), "Sampel merupakan bagian dari jumlah dan karakteristik yang dimiliki oleh populasi tersebut, kesimpulannya akan dapat diberlakukan untuk populasi”. Karena hal tersebut sampel yang digunakan harus berdasarkan representative atau yang mewakili. Pada penelitian ini, yang menjadi sampel adalah konsumen yang telah menempati rumah di perumahan Cinere Parkview, sebanyak 100 responden.

\section{Metode Analisis Data Uji Validitas}

Uji validitas pada penelitian kali ini dengan melakukan pembanding dari nilai $r$ hitung dan nilai $r$ tabel, pernyataan tersebut dikatakan valid apabila memiliki $r$ hitung $>r$ tabel. Untuk mempermudah maka dinyatakan bahwa pernyataan valid apabila nilai Korelasi Corrected Item-Total Correlation > 0,3.

\section{Uji Reliabilitas}

Reliabilitas adalah suatu acuan yang memperlihatkan sampai dimana alat pengukur dapat dipercaya. Uji reliabilitas dilakukan terhadap keseluruhan pernyataan yang dapat dikatakan secara valid. Pengujian reliabilitas dapat dilakukan dengan menggunakan metode Cronbach's Alpha. "Reliabilitas terpenuhi jika nilai Cronbach's Alpha > 0,6" menurut Santoso (2000:72). Kategori instrumen penelitian dalam penelitian ini menggunakan skala Likert dengan pilihan jawaban responden terhadap item pertanyaan berupa: 1) Sangat Tidak Setuju, 2) Tidak Setuju, 3) Cukup Setuju, 4) Setuju, 5) Sangat Setuju.

\section{HASIL DAN PEMBAHASAN \\ Hasil Penelitian \\ Uji Validitas dan Reabilitas Lokasi $\left(X_{1}\right)$}

Variabel lokasi yang terdiri dari 8 butir validitas pertanyaan diuji dengan membandingkan nilai $r$ hitung dan $r$ tabel (corrected Item-Total). Dengan responden
100 maka taraf signifikan 0.05 maka $r$ tabel 0,1966 , hasil uji validitas variabel dan uji realibilitas terhadap variabel Promosi yang terdiri dari 8 pertanyaan atau pernyataan yang valid diperoleh nilai Cronbach's Alpha sebesar 0,891. Karena nilai Cronbach's Alpha lebih besar dari pembanding $(0,891>0,600)$, maka sebagai acuan yang dijadikan suatu keputusan dalam pengujian realibilitas di atas, dapat diartikan bahwa 10 atau item pernyataan atau pertanyaan angket untuk variabel lokasi adalah reliabel atau konsisten.

Uji Validitas dan Reabilitas Harga $\left(\mathrm{X}_{2}\right)$

Data variable harga yang terdiri dari 5 butir validitas pertanyaan diuji dengan membandingkan nilai $r$ hitung dan $r$ tabel (corrected Item-Total). Dengan responden 96 maka taraf signifikan 0.05 maka $\mathrm{r}$ tabel $0,1966 \mathrm{Uji}$ realibilitas terhadap variabel kepuasan yang terdiri dari 5 pertanyaan atau pernyataan yang valid diperoleh nilai Cronbach's Alpha sebesar 0,860 Karena nilai Cronbach's Alpha lebih besar dari pembanding $(0,860>$ $0,600)$, maka sebagai acuan yang dijadikan suatu keputusan dalam pengujian realibilitas di atas, dapat diartikan bahwa 10 atau item pernyataan atau pertanyaan angket untuk variabel harga adalah reliabel atau konsisten.

\section{Uji Validitas dan Reabilitas Promosi ( $\left.X_{3}\right)$}

Data variable harga yang terdiri dari 6 butir validitas pertanyaan diuji dengan membandingkan nilai $r$ hitung dan $r$ tabel (corrected Item-Total). Dengan responden 100 maka taraf signifikan 0.05 maka $r$ tabel $0,1966 \mathrm{Uji}$ realibilitas terhadap variabel promosi yang terdiri dari 6 pertanyaan atau pernyataan yang valid diperoleh nilai Cronbach's Alpha sebesar 0,883, karena nilai Cronbach's Alpha lebih besar dari pembanding $(0,883>$ 0,600), maka sebagai acuan yang dijadikan suatu keputusan dalam pengujian realibilitas di atas, dapat diartikan bahwa 10 atau item pernyataan atau pertanyaan angket untuk variabel promosi adalah reliabel atau konsisten. 


\section{Pembahasan}

Pengukuran pada tiap variabel yang menggunakan kuesioner yang kemudian dilakukan pengembangan dengan beberapa faktor pada setiap variabel penelitiannya. Berdasarkan hasil uji validitas terhadap setiap variabel penelitiannya, diketahui bahwa secara keseluruhan pada item-item yang sudah ditentukan pada variabel penelitian dapat dinyatakan valid. Dengan melakukan pengujian reliabilitas dapat diketahui bahwa keseluruhan item penyataan telah sah pada setiap variabel penelitian yang dilakukan hal tersebut terlihat berdasarkan reliabilitasnya. Kuesioner dapat dikatakan valid dan reliabel maka kuesioner penelitian merupakan alat yang dapat dipertanggungjawabkan untuk mengukur setiap variabel penelitian yang diteliti. Setelah data dinyatakan valid dan reliabel selanjutnya data diolah dengan melakukan uji-uji lainnya dan diperoleh hasil penelitian adanya analsis terhadap lokasi, harga, dan promosi terhadap keputusan pembelian rumah di Perumahan Cinere Parkview.

\section{Analisis Lokasi terhadap Keputusan Pembelian Rumah di Perumahan Cinere Parkview}

Berdasarkan uji t (parsial) nilai thitung variabel lokasi yang diperoleh sebesar 1,708 dengan nilai sig. 0,005 sehingga $\mathrm{t}$ hitung $>\mathrm{t}$ tabel $(1.708>$ $1,98498)$ dan nilai sig < nilai probabilitas sebesar $(0,081<0,05)$ maka dapat disimpulkan Ho diterima dan Ha ditolak. Nilai tersebut menunjukkan bahwa variabel lokasi tidak berpengaruh secara signifikan terhadap keputusan pembelian rumah di perumahan Cinere Parkview.

\section{Analisis Harga terhadap Keputusan Pembelian Rumah di Perumahan Cinere Parkview}

Berdasarkan uji t (parsial) nilai thitung variabel harga yang diperoleh sebesar 1,708 dengan nilai sig. 0,87 sehingga t hitung $>\mathrm{t}$ tabel sebesar $(1,708$ $>1,98498$ dan nilai sig < nilai probabilitas sebesar $(0,87<0,05)$ maka dapat disimpulkan Ho diterima dan Ha ditolak.
Nilai tersebut menunjukkan bahwa variabel harga tidak memiliki pengaruh secara signifikan terhadap keputusan pembelian rumah di Perumahan Cinere Parkview.

\section{Analisis Promosi terhadap Keputusan Pembelian Rumah di Perumahan Cinere Parkview}

Berdasarkan uji $t$ (parsial) nilai $t$ hitung variabel harga yang diperoleh sebesar 1,913 dengan nilai sig. 0,59 sehingga $t$ hitung $>\mathrm{t}$ tabel sebesar $(1,913$ $>1,98498$ dan nilai sig < nilai probabilitas $(0,59<0,05)$ maka dapat disimpulkan Ho diterima dan Ha ditolak. Nilai tersebut menunjukkan bahwa variabel harga tidak berpengaruh secara signifikan terhadap keputusan pembelian rumah di Perumahan Cinere Parkview.

\section{KESIMPULAN \\ Kesimpulan}

Lokasi memiliki pengaruh terhadap keputusan pembelian rumah yang berlokasi di Perumahan Cinere Parkview, karena lokasi memliki pengaruh positif dan tidak signifikan terhadap suatu keputusan dalam melakukan pembelian. Harga memiliki pengaruh terhadap keputusan pembelian rumah di Perumahan Cinere Parkview, karena harga memliki pengaruh positif dan tidak signifikan terhadap keputusan pembelian. Promosi memiliki perpengaruh terhadap keputusan pembelian rumah di Perumahan Cinere Parkview, karena promosi memiliki pengaruh positif dan tidak signifikan terhadap keputusan pembelian.

\section{Saran}

Saran yang akan diberikan antara lain: 1) Untuk lokasi pada perumahan, developer harus lebih merawat lingkungan di Perumahan Cinere Parkview dan dapat dipastikan agar tidak terjadi banjir aliran pembuangan limbah rumah tangga. 2) Pihak management hendaknya memikirkan masalah harga dan melihat daya saing pada perumahan pesaing di daerah Cinere. 3) Dalam upaya meningkatkan keputusan pembelian, 
pihak developer sebaiknya membuat promosi yang lebih menarik dan meningkatkan intensitasnya, memberikan informasi yang sejelasjelasnya terhadap konsumen.

\section{DAFTAR PUSTAKA}

Alma, B. (2014). Manajemen Pemasaran dan Pemasaran Jasa. Bandung: Alfabeta.

Kotler, P. \& Keller, K. L. (2009). Manajemen Pemasaran, Jilid I, Edisi ke 13. Jakarta: Erlangga.

Santoso, Singgih. (2000). Uji Validitas dan Reabilitas Data. Jakarta: Alfabeta.

Swastha, B., \& Irawan. (2008). Manajemen Pemasaran Modern, Edisi Kedua. Yogyakarta: Liberty Offset.

Stanton, William. J. (2000). Prinsipprinsip Pemasaran, Jilid 1, Edisi ke 3. Alih Bahasa oleh Yohanes Lamarto. Jakarta: Erlangga.

Sugiyono. (2010). Metode Penelitian Pendidikan Pendekatan Kuantitatif, kualitatif, dan R\&D. Bandung: Alfabeta.

Tjiptono, Fandy. (2008). Strategi Pemasaran, Edisi Ketiga. Yogyakarta: Andi. 